\title{
HTLV-1 Versus HIV: 40 years of Challenges from Discovery to Treatment for Human Retroviruses and Neurological Implications
}

Amanda L. Abbas ${ }^{1,2}$, Rosa M. Marcusso ${ }^{3}$, Augusto Penalva ${ }^{3}$, Vivian P. de Almeida ${ }^{1}$, Carolina Rosadas $^{4}$, Rogério N. Motta ${ }^{1}$, Marzia Puccioni-Sohler ${ }^{1,5^{*}}$

${ }^{1}$ Universidade Federal do Estado do Rio de Janeiro, Rio de Janeiro, Brazil; ${ }^{2}$ Universidade do Estado do Rio de Janeiro, Rio de Janeiro, Brazil; ${ }^{3}$ Instituto de Infectologia Emilio Ribas, São Paulo, Brazil; ${ }^{4}$ Imperial College of London, United Kingdom; ${ }^{5}$ Universidade Federal do Rio de Janeiro, Rio de Janeiro, Brazil.

Address correspondence to:

Marzia Puccioni-Sohler

Universidade Federal do Estado do Rio de Janeiro (UNIRIO),

Rua Mariz e Barros 775

Rio de Janeiro 20270-004

Brazil

Email:m puccioni@yahoo.com.br 
The human T-cell lymphotropic virus type 1 (HTLV-1) was the first retrovirus isolated in humans (1980) contributing to the rapid identification of human immunodeficiency virus (HIV) in 1983. ${ }^{1,2}$ Both retroviruses share the same transmission routes (sexual contact, contaminated blood breastfeeding and perinatal). Screening of pregnant women and blood/tissue donors have been shown to be an efficient strategy to prevent the transmission of HTLV-1 and HIV. ${ }^{2,3,4}$ However, while HIV testing is routinely performed, HTLV-1 testing is not mandatory worldwide. ${ }^{2,3,4}$

HTLV-1 infection is endemic in many regions of the world predominantly in southwestern Japan, the Caribbean islands, Central and South America, sub-Saharan Africa, Melanesia and the Middle East. ${ }^{4}$ It is estimated that approximately 5-10 million people are infected with HTLV-1 worldwide. However, there are many areas of the world, where HTLV-1 prevalence was never studied ${ }^{4}$. In most countries, notification of HTLV-1 infection is not compulsory, while this is not true for HIV infection. ${ }^{2,4}$ HIV infection has a well known worldwide distribution with higher prevalence in Africa, Caribbean, Eastern Europe, Central Asia and Latin America. According to worldwide data from UNAIDS, 37.9 million people are living with HIV. $^{3}$

HTLV-1 infection can lead to the development of severe neoplasia (adult T cell leukaemia--lymphoma) or chronic inflammatory diseases (neurological disorders, uveitis, conjunctivitis, sicca syndrome, interstitial keratitis, Sjogren's syndrome, Hashimoto's thyroiditis and Graves' disease, pulmonary disease, infective dermatitis, myositis and arthritis, among others) in about $5-10 \%$ of infected individuals. ${ }^{1,4}$ HTLV-1-associated myelopathy/tropical spastic paraparesis (HAM/TSP) is a progressive neurological disorder characterized by weakness and spasticity generally associated with low back pain and neurogenic bladder. Ten years after disease onset, $30-50 \%$ of patients progress to a wheelchair and $45 \%$ are unable to walk without crutches. ${ }^{4}$ In our cohort of 47 patients with HAM/TSP in Rio de Janeiro city, $40 \%$ had rapid progression, $51 \%$ slow progression, $9 \%$ very slow progression. The average time between the onset of symptoms and the neurological diagnosis was $6.09 \pm 6.13$ years. ${ }^{5}$ The majority $(66 \%)$ of patients were restricted to a wheelchair. $^{5}$ In a different context from HIV, many healthcare professionals remain unaware of an HTLV-1 infection, as well as the long period of viral incubation or the development of associated diseases. AIDS is the advanced clinical manifestation resulting 
from an immunodeficiency condition caused by HIV. ${ }^{2}$ Its main feature is the severe suppression of T-cell-mediated immunity, which makes the individual susceptible to opportunistic infections and secondary neoplasms. ${ }^{2}$ In addition, neurological complications of HIV infection include conditions such as HIV-associated neurocognitive disorder (HAND), HIV-associated vacuolar myelopathy (MV) and polyneuropathy. ${ }^{2}$ Since the $1980 \mathrm{~s}$, numerous antiretroviral medications (ART) have been tested and introduced for HIV treatment, leading to longer survival of HIV infected individuals. ${ }^{2}$ Unfortunately, there is no specific treatment or vaccine for HTLV-1 infection. ${ }^{4}$ Successful public health policies applied to HIV infection have not been implemented to prevent HTLV-1 infection. Overall, HTLV-1 infection and associated diseases should be considered neglected as they are endemic in low-income populations, receive reduced investment in research, in drug production and control.

\section{Competing interests}

The authors declare no conflict of interest. 


\section{References}

1. Poiesz BJ, Ruscetti FW, Gazdar AF, Bunn PA, Minna JD, Gallo RC. Detection and isolation of type $\mathrm{C}$ retrovirus particles from fresh and cultured lymphocytes of a patient with cutaneous T-cell lymphoma. Proc Natl Acad Sci U S A. 1980;77:7415-9.

2. Grmek MD. History of AIDS: The emergence of a modern pandemic. Pronceton, NJ: Princeton University Press, 1990.

3. UNAIDS Brasil - Website institucional do Programa Conjunto das Nações Unidas sobre HIV/AIDS (UNAIDS) no Brasil. [Internet]. UNAIDS Brasil. [cited 2019 Dec 10]. Available from: https://unaids.org.br/

4. Gessain A, Cassar O. Epidemiological Aspects and World Distribution of HTLV-1 Infection. Front Microbiol 2012;3:388.

5. Abbas AL. Avanços no conhecimento da história natural da infecção do HIV em comparação a outro retrovírus. Foco na Mielopatia associada ao HTLV-1.M.Sc. Thesis, Universidade Federal do Estado do Rio de Janeiro, Rio de Janeiro, Brazil, 2019. 